Published as: Kleine Staarman, J. (2009). The joint negotiation of ground rules: establishing a shared collaborative practice with new classroom technology. Language and Education, 23(1), 79-95.

\title{
Pre-published draft of: The joint negotiation of ground rules: establishing a shared collaborative practice with new educational technology
}

\author{
Judith Kleine Staarman \\ University of Exeter, UK \\ Email: j.kleine-staarman@exeter.ac.uk
}

Running headline: The joint negotiation of ground rules

\begin{abstract}
Classroom discourse is structured by socially accepted ways in which knowledge is presented and by established procedures for carrying out educational activities. However, the underlying linguistic and social ground rules are usually implicit, for students as well as for teachers. The implicitness of these ground rules has been attributed to students' failure to successfully participate in educational discourse. In this paper, I describe a research project in which primary students jointly negotiated ground rules for working together in an online discussion forum. The aims of the study were to examine a) how collaborative practices were created in interaction and b) how participants made visible to each other what counted as appropriate collaborative discourse. The findings indicate that there are many implicit ground rules in place
\end{abstract}


when a new mode of communication is introduced in the classroom. Moreover, students and teachers do not always share the same (implicit) understanding about what is and is not an appropriate communicative action in new learning environments. One of the conclusions that can be drawn from the data is that when introducing new communication technology in classrooms a new educational genre of communicating needs to be defined and underlying ground rules need to be re-established within the particular educational context.

Keywords: collaborative learning, educational technology, classroom dialogue, ground rules, sociocultural theory, primary schools

\section{Introduction}

Education can be described as a cultural process, following specific cultural routines and conventionalised ways of using language (Nuthall, 2005). These conventionalised ways of using language, with their own specific ground rules, represent socially accepted ways in which knowledge is presented in schools, as well as the procedures for carrying out educational activities, such as problem solving and other tasks. In classrooms, teachers guide students to become active members of their communities by creating contextual and discursive frameworks for educational activities. However, the underlying ground rules often remain implicit, both for teachers and students, and they are seldom explicitly negotiated in the classroom. The implicitness of educational ground rules and the lack of students' awareness of them have been cited as important inhibiting factors for children's ability to participate successfully in educational discourse (Edwards \& Mercer, 1987).

There has been a range of research illustrating the complex situated nature of teaching and learning processes in classrooms; in particular how context, roles, subject 
area, content, text, and meaning are socially constructed by teachers and students, and what members of a classroom need to know, understand or interpret in order to do well (Heath, 1983; Kantor, Green, Bradley, \& Lin, 1992; Floriani, 1993; Green \& Dixon, 1993; Gutierrez, 1993; Heras, 1993; Castanheira, Crawford, Dixon, \& Green, 2000; Kumpulainen, Vasama, \& Kangassalo, 2003; Yeager, 2006). This line of research focuses specifically on what members of classrooms themselves signify as socially and academically significant (Green, 2006). In the current paper, a similar perspective has been used to examine the trajectory of children's collaborative activities in and around an ICT learning environment called 'Knowledge Forum' (Scardamalia, Bereiter, McLean, Swallow, \& Woodruff, 1989) in order to gain a better understanding of both the underlying implicit ground rules for working in the online environment and the negotiation, between the teacher and the students, of new ground rules for working in $\mathrm{KF}$. The research draws on a larger study in which a series of eight lessons were designed with the general aim of developing students' awareness of how to use language to work well together, both in small groups around the computer and in the online environment. This was done through various online and offline activities in which shared 'ground rules' for working together in $\mathrm{KF}$ were established. The lessons were adapted from the Thinking Together approach, as developed by Dawes, Mercer and Wegerif (2000). This approach signifies a way of making explicit 'what counts as appropriate collaboration' in the classroom. For the participating teacher, the aim for negotiating shared ground rules for collaborating in $\mathrm{KF}$ was that these ground rules may begin to to serve as an explicit and shared communicative and contextual resource, which in turn might enable students to work together more effectively (see for example Mercer \& Sams, 2006; Mercer, Dawes, Wegerif \& Sams, 2004). However, the analyses for this paper were not undertaken to assess the effects of a ground rules approach on learning outcomes and thus the question whether the students discussed more effectively after the lessons was beyond the scope of this paper. Rather, the aim of the current research was to find out 
how new collaborative practices were created in interaction, and how participants made visible to each other what counted as appropriate collaborative practice.

\section{Theoretical Background}

\section{The temporal and contextual nature of language}

The inherent sociocultural nature of discursive activities and dialogue was highlighted by Bakhtin (1999, p. 127) through his notion that utterances are never isolated acts of meaning but always contextualised by the specific goals and conditions of the activity. In this respect, Gee and Green (1998) use the term reflexivity, by which they mean "the way in which language always takes on a specific meaning from the actual context in which it is used, while, simultaneously, helping to construct what we take that context to mean and be in the first place" (Gee \& Green, 1998, p. 127). In addition, Mercer (in press) argued that in any specific interactional context, two temporal dimensions of interaction are important: 1) a dynamic dimension and 2) a historical dimension. The dynamic dimension refers to the ongoing creation of shared history or common understanding by interlocutors as they interact. The historical dimension relates to the particular institutional, cultural and social context in which the interaction takes place. For people to be able to interact in a meaningful way in events, they have to interpret and recognise the context as a particular 'situation type' and subsequently, they have to make their interpretations known to their co-participants in the event (Wells, 1999).

In addition to the reflexivity as one of the characteristics of language, participants in conversations also need to have some understanding of the distinctive form and content of the language that is used in that particular situation. In this respect, Bakhtin (1999, p. 121) argued that each sphere in which language is used develops its own, 
relatively stable types of particular utterances. These speech genres follow particular ground rules, which reflect the culture and traditions of a specific community (Mercer, 2000). Speech genres and their associated ground rules can, however, also be a source for misunderstanding since people might not be aware of existing ground rules within a community or might lack the history of using the particular ground rules of a community. In this respect, Edwards and Mercer (1987) noted that children's failure to do well in cognitive tasks may sometimes have more to do with the children's inability to grasp what is expected from them, than with a lack of competence. Mercer (1996) elaborated on this notion by making the ground rules of interaction themselves a topic of explicit consideration for both adults and children, which formed the basis of the pedagogic approach that has been used in the current study.

\section{Intertextuality}

From a dialogic perspective, the historical and dynamic dimensions of language are important considerations in two distinct, but related ways. Firstly, every utterance is only one link in a continuing chain of utterances (Mercer, 2000). A particular speech event can be seen as an episode of a 'long conversation', in which participants have created a shared history and context to which they can refer either implicitly or explicitly (Mercer, 2000; Maybin, 2004). The second consideration is that utterances are also dialogic in a sense that they are multivoiced; they represent both the speaker's voice as well as that of other people who have used more or less the same words or patterns of discourse (Wertsch, Tulviste, \& Hagstrom, 1993). Talking and writing can thus be seen as the recycling of other people's language, through which we create our own meanings and sense (Maybin, 2004). Every time people engage in a language event, they refer to past texts (oral or written) and practices (ways of being with, and constructing text) in order to construct the present text and/or to implicate future ones (Gee \& Green, 1998). 
In this respect, the notion of intertextuality is important, which can be seen as the understanding of how people borrow from other linguistic resources in order to accomplish the current action (Scollon, Tsang, Li, Yung, \& Jones, 1997). However, people not only juxtapose linguistic resources; prior contexts with their socially negotiated roles, meanings, relationships and texts can also become resources for people to draw on. Thus, prior contexts can shape the present context and can implicate future ones (Floriani, 1993). In this respect, Bakhtin speaks of heteroglossia to highlight the wider contextual forces that shape the meaning of utterances (Holquist, 1990). Therefore, a notion of intertextuality always includes a notion of intercontextuality, in order to take into account not only the linguistic resources but also the social and cultural factors that are involved when people interact with each other (Bloome \& Egan-Robertson, 1993). Especially in classrooms, this view of intertextuality can be used to show how teachers and students draw on previous activities to create shared understanding, set up new activities and to guide participation in these activities.

\section{Methodology}

The research setting

The empirical grounding for this study comes from data collected within a larger research project in which one of the aims was to develop and examine primary school Computer Supported Collaborative Learning (CSCL) literacy activities. For this reason, discussion-based activities were developed with the help of an online discussion environment called 'Knowledge Forum' (Scardamalia \& Bereiter, 1992). Knowledge Forum (KF) is a database in which participants' contributions are saved and displayed for others to read and respond to. As in other discussion forums there is no pre-defined content, though the software has several integrated features to support argumentation and reasoning, for example by providing textual supports such as 'opinion', 'reason' and 
'evidence' for categorising the written contributions on the basis of the content of the contribution.

In the version of KF used in the project, the contributions are shown in a web-like structure, rather than a linear structure as is more common in online discussion environments. In a web-like structure, contributions are not organised chronologically, but by topic. Contributions are shown on the computer screen as small squares, connected by lines, and annotated with the title and author of the contribution (see Figure 1). By dragging the icons, participants can organise the lay-out of the screen themselves. When a reader clicks on one of the squares, a new window opens to display the actual content of the contribution. The discussion spaces in which children work are called 'views' (Figure 1 is an example of one view). Views in KF are restricted discussion spaces, created by the teacher or by participants to enable discussion about a specific topic or by a particular group of participants.

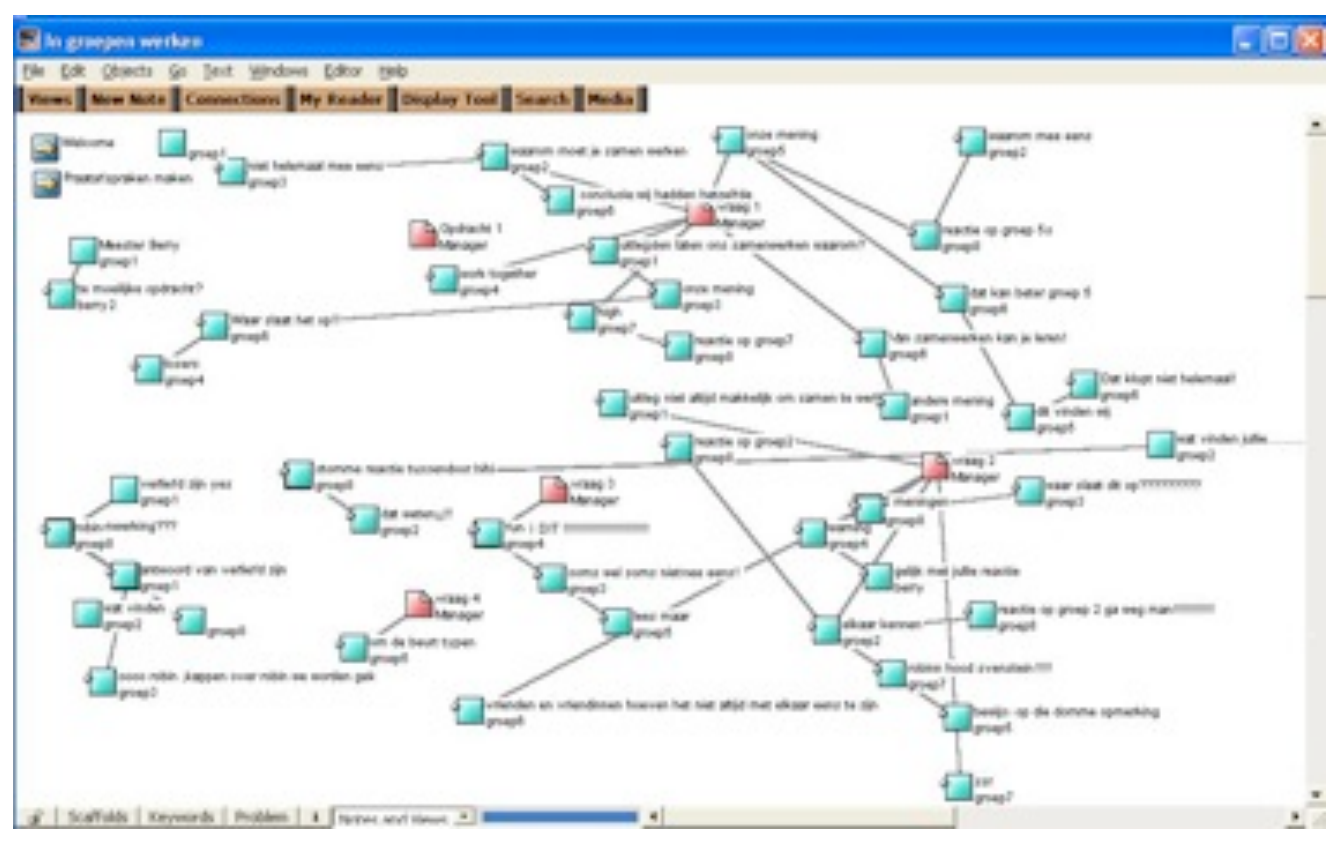

Figure 1: A KF view 
The research school is a modern, medium-sized primary school (around 380 students) in a suburb in the South-East of the Netherlands. The school had fairly recently acquired 30 networked computers which were placed in two areas of the school, one dedicated computer room with 22 computers and one smaller area with 8 computers. All the $\mathrm{KF}$ sessions took place in both computer areas, while before and after $\mathrm{KF}$ sessions the students met in their normal classroom for face-to-face teacher-led whole class discussions. In these sessions, their work in KF was evaluated and topics were discussed further. Online learning environments are commonly used for asynchronous, computermediated interaction between individual participants. The participants in the current study however, worked in groups of three around one computer and they used KF to discuss with other groups of three (from the same class). The reason for this, somewhat artificial setup, was that working in this way enabled the students to combine the specific characteristics of face-to-face discussion in groups with those of asynchronous, written discussions. Earlier research within the same project (Kleine Staarman, 2003) showed that children were less hesitant to give their opinion in online discussions and seemed better able to evaluate their ideas against those of others, when they were able to check their ideas with someone sitting next to them first before posting their ideas to the whole-class online discussion. In addition, writing on the computer tends to help children to develop a better understanding of the writing process since the combination of word processing software and a writing partner can serve to scaffold the students' writing process (Schwartz, Van der Geest, \& Smit-Kreuzen, 1992; Wegerif \& Dawes, 2004).

For the current phase of the project, a series of seven lessons were developed aimed at creating shared understanding between the students and the teacher of what counted as 'good collaboration in KF' for them. This was done through a discussion about the topic of 'working together in KF'. In each lesson, a statement or question around collaboration was discussed in order to gradually move towards a list of shared 
and jointly negotiated and agreed ground rules for working together in KF. Each of the lessons lasted approximately 50 minutes. The students worked in groups of three, formed by the teacher on the basis of ability to work together and ability in speaking and listening.

\section{Data collection}

To enable a close analysis of the classroom talk in its context over time, several types of data were collected. Video recordings were made of all the whole class sections of lessons and of one focal group during group work activities. Two additional focal groups were recorded on minidisk. These focal groups were chosen to represent a range of gender and ability levels. All the written material in connection with the project was collected, including the written messages in the KF database. Additional observational notes were made during each lesson about the general procedure of the lesson, the interaction process within the groups, the way the students worked with the software, and possible relevant topics for the analysis. All the audio and video recordings were transcribed and the transcripts and observational notes were imported in NVivo2, organised, labelled and annotated.

All audible talk, including repetitions and hesitations sounds such as 'eh' were transcribed. To make the transcriptions more readable, standard punctuation was added but notations to depict the pronunciation of utterances or pauses were not used. The transcription symbols that were used are explained below.

\section{Basic transcription symbols}

(inaudible) Inaudible words 


\author{
(laughs) Gestures or other non-verbal actions and contextual \\ information is shown in italics and between brackets \\ [...] Part of transcript left out \\ [ Overlapping speech \\ ... Interruption or continuation after an interruption
}

All the data was analysed in Dutch and translated into English after the analysis. Translation of data is not a transparent process and it invariably involves small changes and subtle shifts in meaning. Especially culturally bound idiomatic meanings are difficult to translate, even for native speakers of both languages. As far as possible, the English translations retain the original Dutch sense and meaning. Native speakers of English were consulted in cases in which I was not sure of the translation of a precise meaning, in order to obtain an as close as possible translation. Due to space restriction, only the English translations are represented in this paper.

\title{
Analysis of the data
}

The methodological approach adopted for this study draws on Interactional Ethnography, in which a key focus is the exploration of the construction of meaning in and through interaction by participants, how participants negotiate events through interaction and how knowledge and texts can become resources for participants' actions (Castanheira, Crawford, Dixon \& Green, 2000). One way of examining links between various activities and events is by tracing the intertextual links the participants make across events. Intertextual links made in collaborative classroom activity can provide an insight into children's practice of making sense of collaborative practices. In the current 
study, the construct of intertextuality was therefore used mainly analytically, to trace the jointly constructed ground rules across various interactional spaces (whole class discussions with the teacher, KF discussions and small group interaction around the computer).

As the research aim was to examine how collaborative practices were created in interaction, and how participants made visible to each other what counts as appropriate collaborative practice, the analysis focused in particular on the process of establishing the ground rules for working together in KF. The analysis followed a three-stage process. First, all the interactional data was categorised in terms of 'interactional spaces' and 'project activities', to enable the representation of a local history of practice and the creation of a trajectory of collaborative work (Floriani, 1993). Interactional spaces (i.e. whole class, small group within whole class, whole class in $\mathrm{KF}$, small group around computer within KF) represented the collaborative contexts in which the students created shared understanding about collaborative practices. In these interactional spaces, students worked with a variety of texts and had the opportunity to engage with various kinds of information, which contributed to the creation of common knowledge. This, in turn, became a resource for the students within the overall trajectory of collaborative practice (Heras, 1993). Following Brilliant-Mills (1993), an activity was defined as a bounded set of discursive events with a common theme or task. Activities could contain one event or span a series of academically linked events, and they could happen within one lesson, or span two or more lessons.

After the first stage of analysis, a procedure of reading and re-reading the data followed in which the content, rather than the structure of the data was analysed. Those discursive events in which the students were talking or writing about collaboration were analysed in depth, which enabled me to uncover clues about how shared understanding about collaborative learning was jointly negotiated between teachers and students over 
time within the trajectory of collaborative practice. The last stage in the data analysis procedure was to establish 'tracer units', which represented jointly constructed units of meaning, which I could 'trace' through the data (Lin, 1993). For this process, lexical analysis software was used (WordSmith Tools).

\section{Results}

What counts as good collaboration?

By juxtaposing the activities and interactional spaces, and following through various tracer units within them, I aimed to illustrate how collaborative practices were created in interaction, and how participants made visible to each other what counts as appropriate collaborative practice. The following three episodes exemplify the way in which jointly constructed texts served as a shared frame of reference in various activities across interactional spaces. The first episode, presented below, is a sequence of six $\mathrm{KF}$ contributions, in which four different groups of students are involved.

Specific transcription notes:

Bold indicates the title of the contribution, while underlined indicates 'reasoning supports' included in KF. The first contribution in this episode is written as a first (new) contribution, while the others are its responses.

Episode 1

Being in love 
Being in love yes: by group 1

I would like to know: What do you think about being in love and why???????????????????

Answer of being in love: by group 1

opinion: our opinion is that we ask you something about what you think about being in love??????? And we think being in love is dead wicked and we like the boys in this class

Rens: by group 8

I like Rens because I like him

For Kristel: by group 1

Opinion: we think he is a coconut and would fit you really well Kristel.

eeeerrhh rens, shut up about rens we are going nuts: by group 4

Explanation: why are we talking about this it really makes no sense 
Reason: Kristel, why are you talking about Rens the whole time?

An example such as Episode 1 would often be classified as off-task talk. However, while analysing the face-to-face discussion of one of the groups, my attention was drawn to the phrase 'being in love'. This was certainly not a topic one would normally expect in an educational discussion on collaborative learning. I decided to trace this topic back to its origins and hence the phrase 'being in love' became a 'tracer unit' of which the current episode is its origin. In the following episodes, I will show how this notion was taken up in subsequent activities by the students and the teacher. In Episode 1, the historical dimension of language is visible through the shared understanding that is assumed in some of the messages, for example in the last contribution in which Group 4 asks why Kristel is talking about Rens 'the whole time'. In this last message, both indexicality (the word 'this', which is referring to the current topic of discussion), and contextualisation cues can be found in the text, illustrating the verbal nature of written dialogue in an online discussion forum. The contextualisation cue shows the student's understanding of what the current exchange is about, and which topics they find appropriate for discussion. In this respect, this cue illustrates the initial awareness of the students about what counts as an appropriate discussion topic in $\mathrm{KF}$ for them at that particular moment in time.

The following episode is taken from a discursive event later in the project in which children discussed in groups of three what they would consider good ground rules for working in KF.

\section{Episode 2}

What is nonsense? 
1 James Well I mean that you shouldn't do nonsense [eh

2 Gavin [If

3 David [That you eh

you, no ... But what is nonsense? [What is the

problem?

don't...... No, is talking about being in love, is that

nonsense? It can be, can't it? That could be a very

normal topic, is that nonsense?

5 James Yeah, ok.

[...]

6 Gavin I think that you, I would say, I think that you have

to talk about sensible topics, but yes, what is a

sensible topic?

7 James Eh, do you agree with that David?

8 Gavin Yes, we could write [down what we think that you

9 David

should talk about serious topics.

\begin{tabular}{|c|c|c|}
\hline 10 & Gavin & $\begin{array}{l}\text { here as well. } \\
\text { But what is a sensible topic? }\end{array}$ \\
\hline \multirow[t]{6}{*}{11} & James & Yes, here, look, that's what they are asking, they \\
\hline & & are just going to ask that, here it says, we think \\
\hline & & that you have to use the programme seriously. \\
\hline & & That means that you have to do serious with \\
\hline & & serious topics and not about eh, are you in love \\
\hline & & with eh, Harissa or something. \\
\hline 12 & Gavin & Well, that could be a good topic couldn't it? \\
\hline 13 & James & Yeah, ok, when you are talking about being in \\
\hline 14 & David & $\begin{array}{l}\text { love. } \\
\text { That is not about this programme, that is about }\end{array}$ \\
\hline
\end{tabular}

[Yes, no, but we had that 
In this Episode, the students are arguing for the fact that certain topics might be appropriate to talk about in particular contexts, but not in a classroom context. An implicit intertextual link (Kleine Staarman, Aarnoutse \& Verhoeven, 2003) to the event in Episode 1 is made by Gavin in Line 4, when he refers to 'talking about love'. This intertextual reference is taken up by the others and they start reasoning about the appropriateness of a topic such as 'love'. In doing so, the students display a sophisticated understanding of the concept of genre, most explicitly by David in the last sentence in which he says: “That's not about the programme, that is about the outside world", emphasising that he thinks $\mathrm{KF}$ is a school-based activity, for which certain topics are not appropriate while the same topics might be appropriate in other contexts.

The same text is referenced once more, this time in one of the later activities in which the teacher jointly negotiates with the children their own set of around six ground rules for working together in KF. In this activity, the interactional space is a whole class discussion. The teacher has just asked the students about the ground rules that they have discussed in their groups.

\section{Episode 3}

\section{Going steady}

1 James Perhaps someone thinks something is a really useful topic and the other would think that that would be nonsense, that it could probably be that someone finds it sensible to ask everyone with whom they are going steady or with whom you would want to go steady with, yes, it could be that someone is very interested in that 
2 Teacher Yeah, but if you would take the example of two

lessons ago, what was the question then?

3 James I can't remember

4 Teacher Peter?

5 Peter Yes, it was about collaboration, and that you, you have to respond to a note, yeah, that you are not going to talk about going steady with someone or something

6 Teacher Ok, so you have been given an assignment, or a theme, or whatever, so you have to make sure you stick to the topic, which was what you

$7 \quad$ Vicky $\quad$ Yes meant as well Vicky?

[...]

8 Teacher Could you rephrase this rule so that it contains a bit of what Vicky was trying to say, but so that it is a bit more useable?

9 Maud Ehm, yeah, perhaps, so you have to (...), if youTeacher writes on decide on the topic you should talk about thatblackboard: With too everything you write, keep the topic in mind 10 Teacher What if I would write it down like this, can youChildren nod yes tell me if this is ok?

In Episode 3, the students are again arguing that some topics might be more appropriate in certain situations than others. After an initiation by James, the teacher (who has read all the KF contributions) makes an explicit intertextual link to the written $\mathrm{KF}$ contributions in turn 2. She uses the intertextual reference to frame and contextualise the current discussion (Swann, Deumert, Lillis \& Mesthrie et al., 2004). In doing so, she also steers the discussion towards the formulation of a shared ground rule, based on the idea that the children should remind themselves of the topic of discussion, before 
contributing. Although the teacher eventually formulated the ground rule on the whiteboard, it was initiated and shared by the students. The role of the teacher in establishing what counts as appropriate action in the classroom is evident. However, jointly negotiated interactional conventions are not fixed entities and, as I will show in the following two episodes, the children re-negotiated them in their discussions.

Episode 4 is taken from one of the first activities in the project, which took place during the first lesson. The main aim for the teacher in this activity was to introduce KF as an online tool for discussing together. Just before the discursive event, the teacher showed the students how to open KF on the computer and in the event she shows the children how to write a response to another note in KF.

\section{Episode 4 \\ Explaining KF}

1 Teacher We don't think so - what if this would be the A KF contribution is first note that someone opens, and it would projected on the say we don't think so? So perhaps that should whiteboard. Teacher be phrased slightly differently. [...] We don't sits at a table with a think so, that is a bit unclear I think. How laptop computer in could we, eh, write this down? Susan? the back of the classroom, children

2 Susan Ehm, you should say (inaudible) are facing the

3 Teacher You think this is all right? Mats? whiteboard. To the rest of the class 
4 Mats Yes, then you should first eh, from a question

that you are going to answer, you should say

that first, than ...

5 Teacher $\quad$... That one has to come back in this, right? In

7 Teacher So what would we say here? Mats?

8 Mats We think that the best reader [is not ...

9 Other students [Is not the

$\begin{array}{lll} & & \text { smartest... } \\ 10 & \text { Mats } & \text {... Eh, not, eh, does not have to be the smartest } \\ 11 & \text { Teacher } & \text { We don't think so said Christel, Yes? } \\ 12 & \text { Student } & \text { We don't think that the best reader can make } \\ & & \text { all the decisions } \\ 13 & \text { Teacher } & \text { Well done }\end{array}$

This episode shows the teacher demonstrating some of the functions of the programme (by use of a laptop and a projector), modelling the process of composing a KF contribution and contributing this to the database. The episode starts with an intertextual link to a previously written contribution, which she uses to create a response and, by asking the students questions, they jointly establish what the content of this response should be. She indirectly valuates the response of a student by asking the same question again, indicating that she ultimately defines what counts as an appropriate contribution to $\mathrm{KF}$ in this particular event. The students are then guided by the teacher towards reformulating their response and it is jointly established (in turns 5 and 6) that an appropriate title for a KF contribution would be one from which the previous question can be deducted. Thus the teacher not only introduces the task and explains the key concepts, but also sets the goals for this and future events. She simultaneously evaluates the group work and establishes new collaborative working procedures for KF. And more importantly, she sets up future activities by introducing ways of working in KF and by 
defining important concepts for these lessons, such as discussion, negotiation and agreement. However, as the following episode will illustrate, the ways of working as defined by the teacher are open to interpretation by the students. In Episode 5 we see a group of three boys discussing how to write and structure their KF contribution.

Episode 5

Referring back to the question

1 Ralph Look, because we don't know, actually, this is

2 Peter

not a fact so it is actually an opinion...

know, we had to refer back to the question.

3 Ralph ... but if you would know exactly that it was like

that, than it would be a reason or an

explanation, but...

4 Peter ... but we have to refer back to the question

$5 \quad$ Chris

because if someone would click on this, [than...

have to put the question in front of it.

6 Ralph No, we don't have to.

7 Peter Yes we do, because otherwise others won't

know, other people have to respond to this

statement again. [...]

8 Peter No, we shouldn't do that now, cos when others

click on that, they won't know whether it is a

statement (inaudible)

9 Ralph But then a line like this would appear?

As we can see from Episode 5, the shared understanding about the formulation of a title in $\mathrm{KF}$ that was jointly established in Episode 4 is not a fixed entity, but a ground rule for 
classroom dialogue that is open for interpretation by participants. The students in Episode 5 renegotiate the rule, and they do not write what was previously considered an appropriate title for a KF response. This discrepancy between the teacher's and students understanding of what counts as an appropriate contribution to the classroom dialogue has been well documented by Edwards and Mercer (1987) who noted that in their research there was a significant divergence between what the students considered appropriate and he criteria for success the teachers applied. The same phenomenon was reported by Gutierrez (1993, pp. 361), who argued that "through their interactions with students, the teachers signalled what they preferred as appropriate actions [...], and what counted as appropriate activity”. However, she also noted that even though jointly negotiated and somewhat predictable patterns of interaction we constructed in the lessons, these patterns remained open for revision and reconsideration, both by the teachers as by the students. What counted as an appropriate title for a response in $\mathrm{KF}$, although explicitly negotiated in the first lesson, became an implicit rather than an explicit ground rule in the current project, as it was not revisited in any of the future activities, neither by the students nor by the teacher.

Another aspect that may influence participants' concept of 'what counts as appropriate' in a particular activity is their understanding of the appropriate speech genre. This is particularly important when a new mode of communication is introduced, as is the case with online learning in schools. In the discussions within the current project, there were many references to MSN language in relation to whether or not this would be an appropriate (sub)genre to use with KF in school. 'MSN language' refers to the use of a particular style of interaction common in chat programmes and resembles current texting language. The following two episodes illustrate the negotiation and renegotiation of what counts as an appropriate contribution to $\mathrm{KF}$ by the students, with regard to the use of MSN language. Episode 6 is taken from a face-to-face discussion in a group of 
three boys.

Episode 6

MSN language

1 Carl Two, yes, I also think MSN language, yeah. I

don't know what you guys think?

2 Roy yeah, I do, you know, understand MSN

3 Paul [I don't really

4 Carl For instance, someone like, eh, just to name

someone, for instance Paul-Ba, eh, Nils or

Thomas, they don't have MSN, no computer

5 Roy Or Jeroen

6 Carl Yeah, they can, they hardly use that and they

7 Roy No

8 Paul I understand it, nah, I understand...

9 Carl I understand it sometimes, [like with 'effe' ['effe' is Dutch slang,

not translated into

English]

10 Roy

[Well, there are

really strange words in it, abbreviations

11 Paul Yeah, and than you do a ' $w$ ' and then an eight

12 Carl Yeah, 'wait', that's what that is

13 Paul Yeah

14 Roy Yeah

15 Carl Or else, eh, ' $\mathrm{f}$ ' $\mathrm{f}$ ' is just 'effe'

16 Paul 'Effe' yeah

17 Carl And then you can do ' $\mathrm{k}$ ' ' $\mathrm{k}$ ', or 'ok'

18 Roy 'o' 'k', yeah

19 Paul Yeah, I don't understand all [that 
[...]

20 Carl Eh, don't use MSN language

21 Paul No MSN, because some kids just don't

understand

In Episode 6, we see three boys reaching agreement about not using MSN language in $\mathrm{KF}$, as they argue that some members of the classroom may not be able to understand it. Initially, Carl and Roy seem to veer towards indifference with respect to using MSN language, unlike Paul who explains that he doesn't really understand it in lines 3 and 19. The others name a few other children in the class who they think might not understand either, perhaps to take the edge of Paul's experience (or lack thereof) and subsequently agree that MSN language may not be suitable to use in their classroom context. This episode illustrates again illustrates how the shared classroom culture is invoked in the students' interaction and signifies how the participatory role of students within the classroom community needs to be acknowledged to understand the ways in which participants jointly construct meaning (Fernández Cárdenas, 2004).

The topic of MSN language found its closure in a later event, which took place in a whole class discussion.

Episode 7

Using understandable language

1 Mats Do not use MSN language

2 Teacher No MSN language (...)

3 Mats Because for episode, not everyone understands for instance when you do W eight, than it says wait, but not everyone knows this. 
4 Teacher No, these are not rebus puzzles. OK. Eva?

5 Eva I [...] would for instance, yeah, not find it a very important rule because, yeah, if you would want to just quickly say 'effe' or something, than, yeah, I mean, some kids might not understand, but I think it's, I don't think it would be really bad if someone would use MSN language.

[...]

6 Other No, neither would I

student

7 Teacher

Gerald

8 Gerald Most of the time, you've got, yeah, I don't think so either really, cos it can of course happen but those really tricky things are not used that often, cos wait, I don’t think you would put in Knowledge Forum 'effe wachten' [transl: just wait]. Most of the time, you're working with the three of you together, so someone will know. If you don't know, you can always ask ...

9 Teacher [But you will have to be able to do this on your own as well, so...

10 Gerald [... and you'll learn from that too

11 Teacher Did you have something about this Paul?

12 Paul Yeah, we also had that some kids just won't understand

13 Teacher So you had this rule too?

14 Paul Yeah, we had it too, because it doesn't really make sense, because you might as well type as much as you like but if you would only use that MSN language, yeah, than no one will get it. But I also don't think it is that important. 
15 Other No

students

16 Paul [But people will have to be able to understand it

17 Teacher $\quad$ though

blackboard:

make sure you

use

understandable

18 Student Yeah, that looks ok, not too many difficult words

language)

19 Teacher Yes, that is incorporated in this too, isn't it?

In this episode, Mats offers a suggestion for a shared ground rule, which he immediately backs up with a reason. The teacher seems to agree with him; other students however are more tentative and although they do seem to agree that everyone should be able to understand, they do not find this an issue that would be worth an explicit ground rule. The teacher does acknowledge this, but does seem to press for a ground rule that would incorporate the use of understandable language, to which the students seem to agree. Subsequently, this becomes one of the class' shared ground rules in line 17. In Line 11, the teacher asks Paul what he had discussed in his group on the issue of MSN language. As we have seen in Episode 6, Paul did not seem to have an issue with respect to letting his partners know that he doesn't understand MSN language in the small group. However, he does not mention this in the whole class situation, and instead generalises the idea to 'some kids won't understand', to which he adds that he doesn't think the rule would be very important. This illustrates that students not only negotiate and renegotiate their shared understanding across various activities but also their roles as classroom participants. In this instance, the option for Paul to 'save face' might have 
moved the joint negotiation of this particular ground rule towards a more general reformulation. A small change in the orientation of one of the students and the associated pattern of interaction can be seen to have a large impact on the interaction (Gutierrez, 1993) and, in this episode, on what counts as an appropriate contribution to $\mathrm{KF}$ in subsequent activities.

\section{Conclusions and Discussion}

Through talk, participants in teaching and learning processes create common knowledge, on which they build in future educational activities (Mercer, 1992). In this paper, I aimed to show how a trajectory of joint meaning making becomes visible, by juxtaposing the various discursive events within and across activities and interactional spaces. People in a conversation only draw from the context what they consider relevant for that particular conversation. Thus people make choices in each conversation, based on what they think counts as contextual and what not. In the same vein, Bloome and Egan-Robertson (1993) pointed out that intertextuality is a social construction which occurs within a cultural context and this context thus influences which and who's texts (or contexts) are juxtaposed, by whom, in which conversation and when. Following this, it can be argued that in collaborative activities, the interaction will be based on what counts as 'good collaborative practice' for the participants. The episodes exemplified how texts that are created in one discursive event may shape future discursive resources which participants use to jointly establish new working procedures. In other words, these discursive events shaped what counted as good collaboration for the participants in this classroom and this, in turn, influenced the kind of interaction and collaboration that took place in the various activities (Green \& Dixon, 1993). 
This study also shows that the emergence of new technology may fundamentally change the nature of the communicative and collaborative processes in classrooms. Moreover, when working with new technology students and teachers draw on implicit ground rules as configurations of implicit discourse conventions that are in place when participants interact. As such, discursive events might become implicitly or explicitly cued by these discourse conventions that are present (Fairclough, 1992). It is when the participants are not aware of the implicit ground rules, or when they are renegotiated by some participants, that classroom discourse may become problematic. Especially in those situations in which discursive ground rules are open for discussion or ambiguous, awareness of these ground rules and agreement about them becomes vital. The introduction of new technologies in classrooms in particular, may give rise to such problems.

It has been argued that computer mediated communication encourages a new type of genre, which combines features of spoken and written modes of communicating (Wegerif, 1998; Yates, 1993; Wertsch, 2002). This may be the reason why its introduction in education can become problematic, as interlocutors can be familiar with the mode of interaction (asynchronous, written communication) but in a different social context. As the episodes above illustrate, the genre of communication, with its associated ground rules then needs to be re-established for the particular social situation in which it is used. Since many students in the current study were familiar with MSN and other forms of online communication, their conventionalised ways of using language in these environments did not match the educational ways of using language the teacher (and some other students) considered appropriate. Thus, although the mode of communication may be familiar, the lack of shared understanding of the genre of communication may lead to false assumptions about participants' communicative competence or their linguistic awareness. Therefore, when introducing new communication technology in schools, educators need to take into account that even 
though students and teachers might be familiar with the new mode of communication, the established and conventionalised genre of communicating with that mode might not be considered appropriate in the classroom and new discursive ground rules may need to be re-established within that particular classroom context.

\section{Acknowledgements}

This research was funded by a grant from the Netherlands Organisation for Scientific Research (NWO). I am grateful for the participation of the teachers and students, who generously lent me an insight in their collaborative processes. I would also like to thank Hector del Castillo Fernandez and Neil Mercer for their constructive comments on earlier drafts of this paper.

\section{References}

Bakhtin, M. M. (1999) The problem of Speech genres. In A. Jaworski and N. Coupland (Eds). The Discourse Reader (pp. 121- 132). London: Routledge.

Bloome, D. and Egan-Robertson, A. (1993) The social construction of intertextuality in classroom reading and writing lessons. Reading Research Quarterly 28 (4), 305-332.

Brilliant-Mills, H. (1993) Becoming a mathematician: Building a situated definition of mathematics. Linguistics and Education 5 (3-4), 301-334.

Castanheira, M. L., Crawford, T., Dixon, C. N. and Green, J. L. (2000) Interactional Ethnography: An approach to studying the social construction of literate practices. Linguistics and Education 11 (4), 353-400. 
Dawes, L., Mercer, N. and Wegerif, R. (2000) Thinking together: A programme of activities for developing thinking skills at KS2. Birmingham: The Questions Publishing Company Ltd.

Edwards, D. and Mercer, N. (1987) Common knowledge: The development of understanding in the classroom. London: Methuen.

Fairclough, N. (1992) Intertextuality in critical discourse analysis. Linguistics and Education 4, (269-293).

Fernández Cárdenas, J. M. (2004). The appropriation and mastery of cultural tools in computer spported collaborative literacy practices. Unpublished Doctoral Thesis, The Open University, Milton Keynes.

Floriani, A. (1993) Negotiating what counts: Roles and relationships, texts and contexts, content and meaning. Linguistics and Education 5 (3-4), 241-274.

Gee, J. P. and Green, J. L. (1998) Discourse analysis, learning, and social practice: A methodological study. Review of Research in Education 23, 119-169.

Green, J. (2006) On learning as a collective and individual accomplishment: (Re) formulating relationships among learning, teaching, discourse and action. Paper presented at the AERA2006, San Francisco.

Green, J. and Dixon, C. N. (1993) Talking knowledge into being: Discursive and social practices in classrooms. Linguistics and Education 5 (3-4), 231-239.

Gutierrez, K. D. (1993) How talk, context, and script shape contexts for learning: A crosscase comparison of journal sharing. Linguistics and Education 5 (3-4), 335-365.

Heath, S. B. (1983) Ways with words. Cambridge: Cambridge University Press.

Heras, A. I. (1993) The construction of understanding in a sixth-grade bilingual classroom. Linguistics and Education 5 (3-4), 275-299.

Holquist, M. (1990). Dialogism: Bakhtin and his world, 2nd edition. London: Routledge. 
Kantor, R., Green, J., Bradley, M. and Lin, L. (1992) The construction of schooled discourse repertoires: An interactional sociolinguistic perspective on learning to talk in preschool. Linguistics and Education 4 (2), 131-172.

Kleine Staarman, J. (2003) Face-to-face talk to support computer-mediated discussion in a primary school literacy practice. Reading, 37 (2), 73-80.

Kleine Staarman, J., Aarnoutse, C. and Verhoeven, L. (2003) Connecting discourses: intertextuality in a primary school CSCL practice. International Journal of Educational Research 39 (8), 807-816.

Kumpulainen, K., Vasama, S. and Kangassalo, M. (2003) The intertextuality of children's explanations in a technology-enriched early years science classroom. International Journal of Educational Research 39 (8), 793-805.

Lin, L. (1993) Language of and in the classroom: Constructing the patterns of social life. Linguistics and Education 5 (3-4), 367-409.

Maybin, J. (2004) Researching children's language and literacy practices in school. In A. Goodwin and A. Staples (eds) Learning to read critically in language and literacy education. London: Sage.

Mercer, N. (1996) The quality of talk in children's collaborative activity in the classroom. Learning and Instruction 6 (4), 359-377.

Mercer, N. (2000) Words and minds: How we use language to think together. London: Routledge.

Mercer, N., Dawes, R., Wegerif, R., and Sams, C. (2004) Reasoning as a scientist: ways of helping children to use language to learn science. British Educational Research Journal, 30, 3, 367-385.

Mercer, N. and Sams, C. (2006) Teaching children how to use language to solve maths problems, Language and Education, 20, 6, 507-528.

Mercer, N. (in press) The seeds of time: The temporal analysis of classroom dialogue. Journal of the Learning Sciences. 
Nuthall, G. (2005) The cultural myths and realities of classroom teaching and learning: A personal journey. Teachers College Record 107 (5), 895-934.

Scardamalia, M., Bereiter, C., McLean, B., Swallow, J. and Woodruff, E. (1989) Computer-Supported Intentional Learning Environments. Journal of Educational Computing Research 5 (1), 51-68.

Scardamalia, M. and Bereiter, C. (1992) An architecture for collaborative knowledge building. In E. deCorte, Linn, M.C., Mandl. H. and Verschaffel, L (eds). Computer - based learning environments and problem solving (pp. 41-67). Berlin Heidelberg: Springer Verlag.

Schwartz, H. J., Van der Geest, T., \& Smit-Kreuzen, M. (1992). Computers in writing instruction. International Journal of Educational Research, 17(1), 37-49.

Scollon, R., Tsang, W. K., Li, D., Yung, V. and Jones, R. (1997) Voice, appropriation and discourse representation in a student writing task. Linguistics and Education 9 (3), 227-250.

Swann, J., Deumert, A., Lillis, T., \& Mesthrie, R. (2004). A dictionary of sociolinguistics. Edinburgh: Edinburgh University Press.

Wegerif, R. (1998) The social dimension of asynchronous learning networks. Journal of Asynchronous Learning Networks 2 (1), 34 - 49.

Wegerif, R. and Dawes, L. (2004) Thinking and learning with ICT. London and New York: RoutledgeFalmer.

Wells, G. (1999) Language and education: Reconceptualizing education as dialogue. Annual Review of Applied Linguistics 19, 135-155.

Wertsch, J. V. (2002) Computer mediation, PBL, and dialogicality. Distance Education $23(1), 105-108$.

Wertsch, J. V., Tulviste, P. and Hagstrom, F. (1993) A sociocultural approach to agency. In E. A. Forman, N. Minick and C. A. Stone (eds) Contexts for learning: 
Sociocultural dynamics in children's development (pp. 336-356). New York: Oxford University Press.

Yates, S. (1993) The textuality of Computer-Mediated Communication: Speech, writing and genre in CMC discourse. $\mathrm{PhD}$ thesis, The Open University, Milton Keynes.

Yeager, B. (2006) Discursively constructing 'talking and writing from evidence' as disciplinary practice in History/Social Science. Paper presented at the AERA2006, San Francisco. 